\title{
Aerosol transport over the Gangetic basin during ISRO-GBP land campaign-II
}

\author{
M. Aloysius, M. Mohan, K. Parameswaran, S. K. George, and P. R. Nair \\ Space Physics Laboratory, Vikram Sarabhai Space Centre, Indian Space Research Organisation, Trivandrum - 695 022, India
}

Received: 17 January 2007 - Revised: 12 December 2007 - Accepted: 19 December 2007 - Published: 26 March 2008

\begin{abstract}
MODIS (Moderate Resolution Imaging Spectroradiometer) Level-3 aerosol optical depth (AOD) data and NCEP (National Centre for Environmental Prediction) reanalysis winds were incorporated into an aerosol flux continuity equation, for a quantitative assessment of the sources of aerosol generation over the Ganga basin in the winter month of December 2004. Preliminary analysis on the aerosol distribution and wind fields showed wind convergence to be an important factor which, supported by the regional topography, confines aerosols in a long band over the Indo Gangetic plain (IGP) stretching from the west of the Thar desert into the Head-Bay-of-Bengal. The prevailing winds of the season carry the aerosols from Head-Bay-of-Bengal along the east coast as far as the southern tip of the peninsular India. A detailed examination of MODIS data revealed significant day-to-day variations in aerosol loading in localised pockets over the central and eastern parts of the Indo Gangetic plain during the second half of December, with AOD values even exceeding unity. Aerosols over the Ganga basin were dominated by fine particles (geometric mean radius $\sim 0.05-$ $0.1 \mu \mathrm{m}$ ) while those over the central and western India were dominated by large particles (geometric mean radius $\sim 0.3-$ $0.7 \mu \mathrm{m}$ ). Before introducing it into the flux equation, the MODIS derived AOD was validated through a comparison with the ground-based measurements collected at Kharagpur and Kanpur; two stations located over the Ganga basin. The strength of the aerosol generation computed using the flux equation indicated the existence of aerosol sources whose locations almost coincided with the concentration of thermal power plants. The quantitative agreement between the source strength and the power plant concentration, with a correlation coefficient 0.85 , pointed to thermal power plants as substantial contributors to the high aerosol loading over the Ganga Basin in winter. The layout of aerosol sources also nearly matched the spatial distribution of the Respirable Suspended Particulate Matter (RSPM), derived from the Central Pollution Control Board (CPCB) data, lending additional support to our inference.
\end{abstract}

Correspondence to: M. Mohan

(mannil_mohan@vssc.gov.in)
Keywords. Atmospheric composition and structure (Aerosols and particles; Pollution - urban and regional) Meteorology and atmospheric dynamics (Synoptic-scale meteorology)

\section{Introduction}

Aerosols are fine solid or liquid particles suspended in the atmosphere, originating both from natural and anthropogenic sources. The potential of aerosols in causing long-term changes in global climate through scattering and absorption of the solar short wave and the terrestrial long wave radiations, as well as through the indirect effects like modification of cloud microphysics and cloud life time is now widely well accepted (Charlson et al., 1992; Haywood and Boucher, 2000; IPCC, 2001). Understanding the dynamics of aerosol generation and transport is essential in determining the spatial and temporal heterogeneity of aerosol radiative forcing (Charlson et al., 1992; Hansen et al., 1997). Space-borne remote sensing is the most effective means for obtaining the global information on natural and anthropogenic aerosols on a routine basis (King et al., 1999; Kaufman et al., 1997a, b). The capability of satellites to monitor changes in aerosol distributions over a large region on a day-to-day basis cannot be matched with ground-based measurements. Since the retrieval of aerosol information from satellite measurements involves a few a priori assumptions, as well as knowledge of sensor calibration and its long-term stability, periodic validations of this data through comparison with collocated ground-based direct measurements (ground truth) is very essential (King et al., 1999; Remer et al., 2002; Chu et al., 2002; Di Girolamo, 2004; Remer et al., 2005; Tripathi et al., 2005) before utilising it for quantitative studies.

Several studies using satellite data, as well as groundbased observations have indicated persistent heavy aerosol loading over the Indo-Gangetic plains (IGP) throughout the year, with significant seasonal variation (Di Girolamo et al., 2004; Prasad et al., 2004, 2006; Ramanathan and Ramana, 2005). Incidence of heavy haze and smog in the northern

Published by Copernicus Publications on behalf of the European Geosciences Union. 
parts of the Indian subcontinent during the winter season has become very common in recent years, particularly over the central to eastern parts of IGP, known as the Ganga basin, appearing as a wide band stretching from north central India into the Head-Bay-of-Bengal (H BoB). Regular measurements carried out by the Indian Central Pollution Control Board (CPCB) also show very large concentrations of suspended particulate matter $\left(\mathrm{PM}_{10}\right), \mathrm{SO}_{2}$ and $\mathrm{NO}_{2}$ over the major cities in and around the Ganga basin (http://www.cpcb. nic.in). Bordered by the steeply rising Himalayas in the north and the Vindhya-Satpura mountain ranges in the south and encompassed by the rivers Ganga, Yamuna and their tributaries, the Ganga basin is a gigantic fluvial plain in the central eastern India. With more than 45 million people residing in this region, the population density is one of the highest in India (Goloub et al., 2001). The land being highly fertile, this is an area of major zone of food production in South Asia and continues to attract human settlement, resulting in uncontrolled urbanisation and industrialisation and consequently, high levels of atmospheric pollution (Ramanathan and Ramana, 2005). Studies carried out with TOMS aerosol data during the period 1979-2000 over the Indian land mass indicated a significant increase in aerosol concentration amounting to as much as $10.6 \pm 4.9 \%$ per decade, a sizeable contribution of which comes from the Ganga basin (Massie et al., 2004).

By and large, aerosols over the Ganga basin are the mineral dust transported by dry winds from the Thar desert in the west and the arid zones of the middle east, mixed with the anthropogenic particulates locally produced by industrial and urban activities (El-Askary et al., 2004, 2006; Dey et al., 2004). As the wind speeds are generally low during the winter season, the transport of mineral dust is less significant and the aerosols are mostly composed of locally generated sulphate and black carbon (BC) particles, confined by the regional topography (Di Girolamo et al., 2004; Venkataraman et al., 2005; Prasad et al., 2006). Large-scale industrial consumption of coal and use of the petroleum products in the transport sector are considered to be primarily responsible for the high emissions of BC and sulphate aerosols (Garg et al., 2001; Reddy and Venkataraman, 2002). At the same time, agricultural biomass burning is not expected to be a major source of aerosols during winter (Di Girolamo et al., 2004). Model studies have indicated that, in the Indian context, increasing amounts of $\mathrm{BC}$ aerosols in the atmosphere can potentially change the monsoon pattern by abnormal heating of the atmosphere through the absorption of solar radiation (Menon et al., 2002; IPCC, 2001; Ramanathan and Ramana, 2005; Venkataraman et al., 2005).

As gas, electricity and petroleum products replaced biofuels for domestic purposes over the years, the significance of biofuels as a dominant source of $\mathrm{BC}$ has diminished (http://pubs.wri.org). But rapid growth of industries with an ever increasing demand for electricity has led to an increase in the number of coal fired thermal power plants, especially over the Ganga basin. Since India is the third largest producer of coal in the world, with $\sim 383$ million tons per year, about $62.3 \%$ of the electric power generation is by coal-based thermal power plants (http://www.coalindia.nic.in). The high ash content $(\sim 40 \%)$ in Indian coal and its incomplete and inefficient combustion in the thermal power plants generate abundant quantities of $\mathrm{BC}$, sulphate and nitrate particulates. Though the transport activities also contribute to the production of these pollutants, because of the newly-introduced standards for the vehicular emissions and the use of fuels like CNG (Compressed Natural Gas), LNG (Liquefied Natural Gas), etc., the contribution from this sector to the total pollutant load is only secondary to that from the thermal power sector (http://envfor.nic.in/soer/2001/ind_air.pdf).

The major objective of ISRO-GBP (Indian Space Research Organisation - Geosphere Biosphere Programme) Land Campaign-II (LC-II), conducted from 1-31 December 2004, was to characterise the aerosols over the Ganga basin during the winter season through continuous monitoring of their physical and chemical properties from eight locations in this region. The present work, which formed an important element of this campaign, was conducted over a study domain $\left(20^{\circ}-27.5^{\circ} \mathrm{N}, 75^{\circ}-87.5^{\circ} \mathrm{E}\right)$ encompassing the Ganga basin, by introducing MODIS derived daily AOD (at $550 \mathrm{~nm}$ ) and the daily NCEP reanalysis winds into an aerosol flux equation with a source/sink term to identify aerosol sources. Prior to the incorporation into the flux equation, the accuracy of MODIS derived AOD over the study domain was assessed through a comparison with the daily mean ground measurements of LC-II at Kharagpur and with the AERONET data at Kanpur.

\section{Comparison of MODIS derived AOD with ground- based measurements}

The MODIS on board NASA's polar Sun-synchronous Terra and Aqua satellites make daily observations at 36 spectral bands in the range $0.41-15 \mu \mathrm{m}$ over land and ocean (Tanré et al., 1997; Kaufman et al., 1997a, 1997b; Remer et al., 2005). The selected parameters for the current study are AOD, the Angstrom exponent and fine mode fraction from MODIS Level-3 gridded $\left(1^{\circ} \times 1^{\circ}\right)$ data. The data contains blank pixels arising from the clouds and highly reflecting land portions (Ackerman, 1998; Remer et al, 2005). Since Terra and Aqua passes are descending and ascending with equatorial crossing local times 10:30 and 13:30, respectively, the cloud conditions could be different in these two data sets. Together with the coverage gaps between the orbits, this results in the set of blank pixels for the two sensors to be different from each other. So we divided the pixels into three types in terms of data content: (i) those having data from both Terra and Aqua, (ii) those having data from either Terra or Aqua, (iii) those without any data. In order to have maximal spatial coverage and the best representation of daily mean aerosol 
data, we combined the data of the two sensors in an optimal manner. For those pixels having data from both the sensors, the mean was taken and for those having data from one sensor, that value was retained.The rest of the pixels were made blank.

Validation exercises carried out by Remer et al. (2005) have confirmed that the AOD values retrieved from MODIS are accurate within an uncertainty limit $(\Delta \tau)$ of $\pm 0.03 \pm 0.05 \tau$ over the ocean and $\pm 0.05 \pm 0.15 \tau$ over the land, where $\tau$ is the true AOD at the locations from direct measurements. However in this work, in order to assess the uncertainties before using them for a detailed analysis, the MODIS derived AOD values were compared with ground-based measurements at Kharagpur $\left(22.3^{\circ} \mathrm{N}, 87.3^{\circ} \mathrm{E}\right)$ and with the data from the AERONET station at Kanpur $\left(26.5^{\circ} \mathrm{N}, 80.4^{\circ} \mathrm{E}\right)$.

During the LC-II, AOD measurements at Kharagpur were conducted at $1020 \mathrm{~nm}$ using a hand-held MICROTOPS-II Ozonometer/Sunphotometer. This instrument provides the AOD with an accuracy \pm 0.03 , by measuring the direct solar radiation and using its internal calibration along with the observer's coordinates and measurement time supplied by the global positioning system (GPS) attached to it (Morys et al., 2001). These observations were performed continuously at $\sim 15$ min intervals, from 08:30 to $16: 00$ local time, strictly avoiding the cloudy sky. Each measurement consisted of four or five individual sub-measurements in quick succession, out of which the lowest value was taken as the clear sky AOD, to eliminate any error arising from the misalignment of the instrument with respect to the Sun, which could result in an unrealistic increase in the AOD. From this, the daily mean AOD and its standard error were estimated. These mean values of AOD were compared with the MODIS derived AOD (at $550 \mathrm{~nm}$ ), after normalising to $1020 \mathrm{~nm}$ (MICROTOPS wave length) using the Angstrom exponent reported in the Level -3 data set.

The AERONET is a network of ground-based automatic Sun-tracking CIMEL Electronic CE-318 Sun-sky radiometers, located all over the globe (Holben et al., 1998, 2001; Eck et al., 2005) established by NASA. Most of the AERONET stations are programmed to operate at $15 \mathrm{~min}$ intervals during the day at eight wavelengths: 340, 380, 440,500, 675, 870, 940 and $1020 \mathrm{~nm}$ (nominal wave lengths). From the measured solar irradiance at the above wavelengths, the radiometer computes the spectral AOD with an observational accuracy of about \pm 0.01 to \pm 0.02 (Holben et al., 1998, 2001). The quality assured AERONET Level-2 AOD at $500 \mathrm{~nm}$ from the AERONET station at Kanpur was compared with the MODIS derived AOD after normalising to $500 \mathrm{~nm}$, employing the MODIS Angstrom exponent, as described above.

The time series of MODIS derived AODs along with MICROTOPS measurements at Kharagpur and also with the AERONET measurements at Kanpur are presented in Fig. 1a and $b$, respectively. The MODIS derived AOD agree fairly
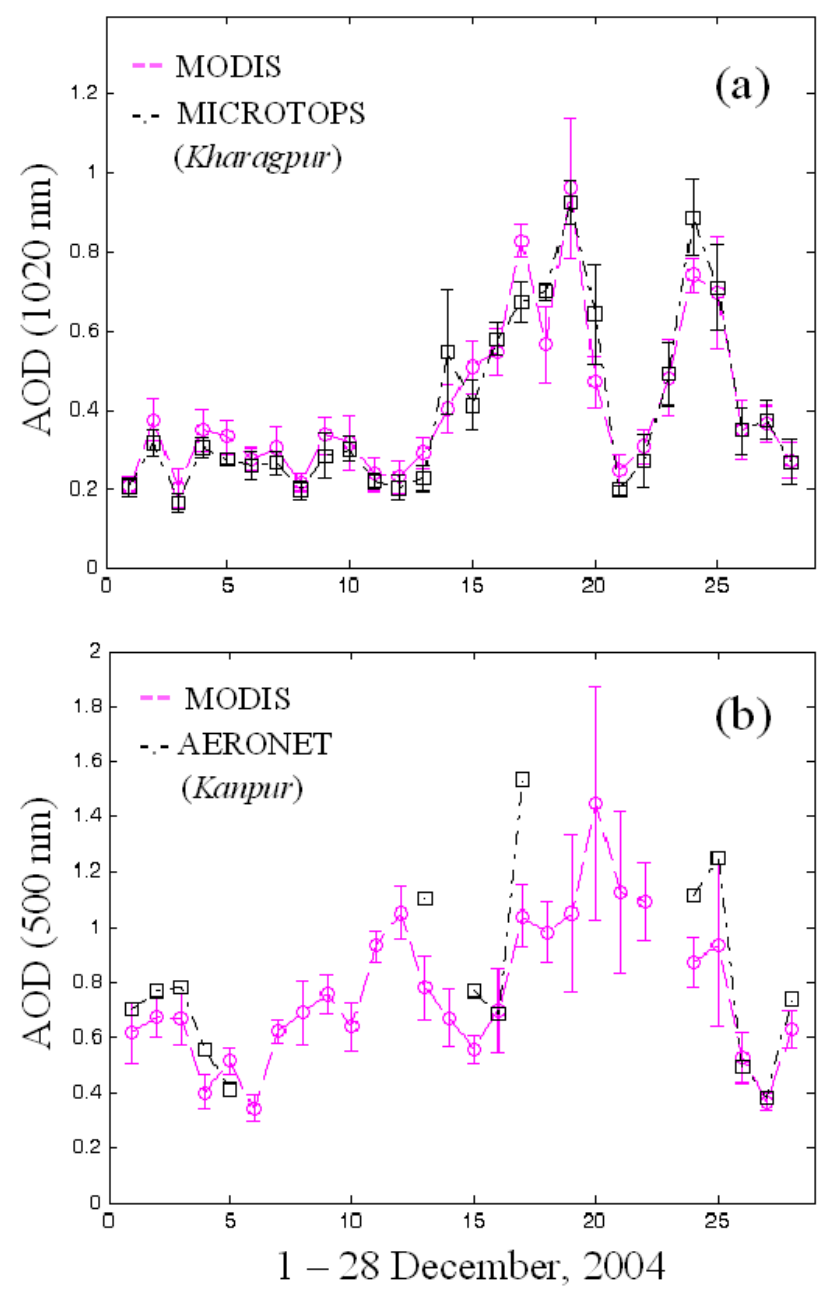

Fig. 1. Time series of MODIS derived AOD normalised to $1020 \mathrm{~nm}$ along with its standard deviation and MICROTOPS measured AOD at $1020 \mathrm{~nm}$ along with its standard error, for Kharagpur (a) and MODIS derived AOD normalised to $500 \mathrm{~nm}$ along with its standard deviation and AERONET retrieved AOD at $500 \mathrm{~nm}$ for Kanpur (b) during LC-II.

well with the direct measurements at both these locations. The corresponding linear correlation coefficients estimated for these two data sets are 0.94 and 0.90 , respectively, which are significant at $p<0.01$ (Fisher, 1970). It is also seen that when MODIS is averaged over the campaign period, MODIS overestimated AOD at Kharagpur by 0.03 while it underestimated AOD at Kanpur by 0.12 with respect to the ground-based measurements. However, these deviations at $\sim 4 \%$ and $\sim 17 \%$, respectively, of the mean AOD during the study period, are well within the uncertainties associated with MODIS retrieval (Remer et al., 2005). 
December, 2004
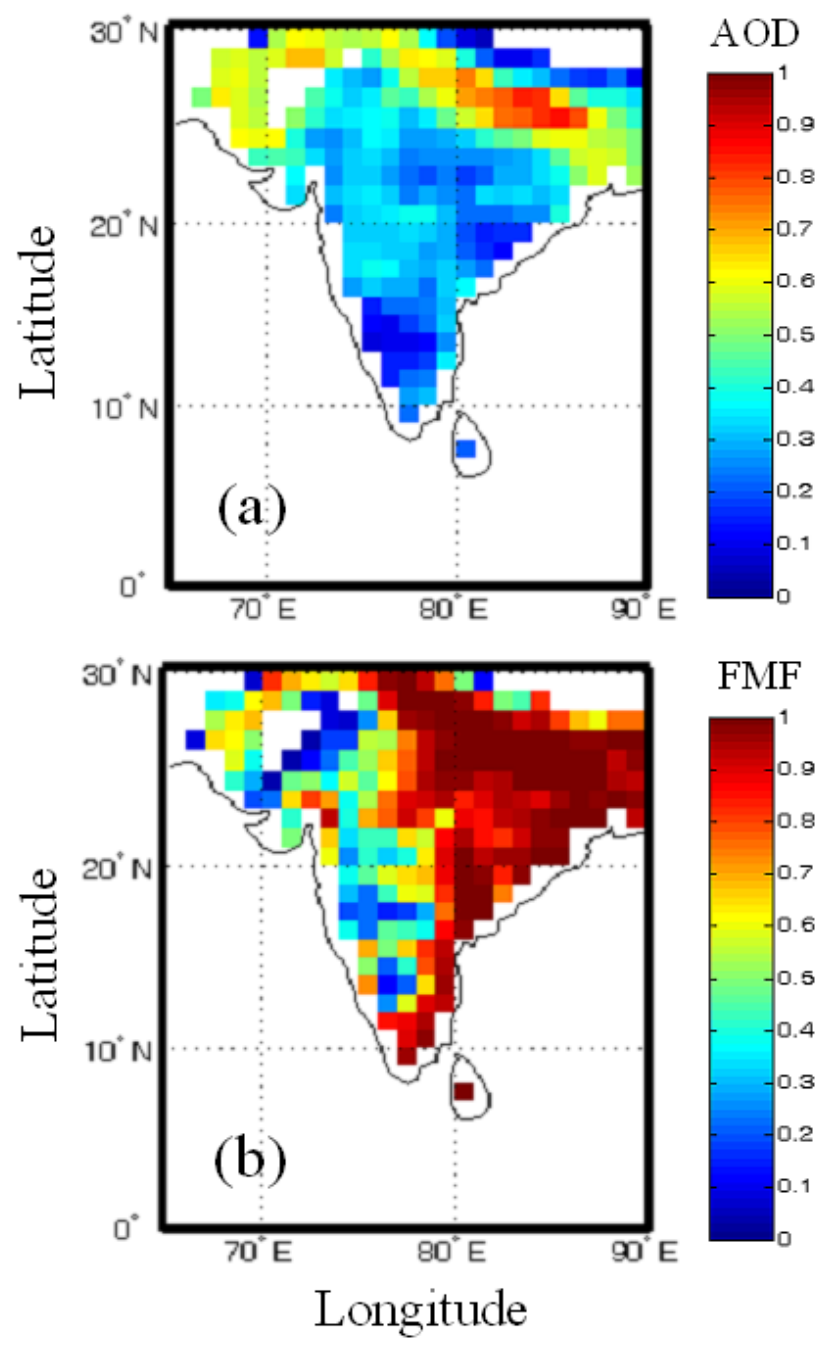

Fig. 2. Mean spatial distribution of MODIS derived AOD at $550 \mathrm{~nm}$ (a) and fine mode fraction (b) during December 2004.

\section{Aerosol generation and transport over Ganga basin}

The MODIS derived AOD and the fine mode fraction averaged over the LC-II period are presented in Fig. 2a and b, respectively. These figures clearly reveal the Ganga basin as a region of exceptionally high aerosol loading, constituted mainly of fine mode particles emphasizing the signature of anthropogenic activities of this region. While the eastern part of the subcontinent up to the tip of the peninsula is dominated by submicron particles, the western part is dominated by large size particles.

When examined on a daily basis, the AOD distributions exhibited large spatial and temporal heterogeneity, probably because of the diversity in the aerosol generation mechanisms, as well as the prevailing meteorological conditions influencing the aerosol concentrations. Aerosols being light particles are lifted up in the air by buoyancy and carried over long distances by wind. As their concentration and transport are strongly influenced by the dynamics of the wind field, any realistic description of aerosol transport by the wind should be made only through a flux continuity equation with a source/sink term representing aerosol generation/loss. By introducing the AOD spatial distribution obtained from satellites and wind fields from a standard atmospheric circulation model into this equation, locations of major aerosol sources (and sinks) can be identified and their strengths quantified.

\subsection{Aerosol continuity equation}

We describe the aerosol flux continuity through the equation $\frac{\partial \rho}{\partial t}+\nabla \cdot[\rho \boldsymbol{v}]=s_{0}$,

where $\rho$ is the aerosol extinction coefficient per unit volume, $v$ is the three dimensional vector wind and $s_{o}$ is the net source representing aerosol emission, dry/wet deposition, impaction, coagulation, diffusion, etc. (Parameswaran 1998; Takemura et al., 2000), all of which are in general, functions of the spatial co-ordinates (i.e. $x, y$ and $z$, respectively) and time $(t)$. The columnar AOD $(\tau)$ is then defined as

$\tau(x, y)=\int_{0}^{\infty} \rho(x, y, z) d z$.

Integrating Eq. (1) over $z$ results in

$\frac{\partial \tau}{\partial t}+\frac{\partial}{\partial x}\left[\int_{0}^{\infty} \rho u d z\right]+\frac{\partial}{\partial y}\left[\int_{0}^{\infty} \rho v d z\right]=S(x, y, t)$,

where $u$ and $v$ are the zonal and meridional winds and $S$ is the column integrated net source.

The daily values of AOD from MODIS and the daily average wind field at seven levels (1000 to $400 \mathrm{hpa}$ ) obtained from NCEP reanalysis were incorporated into Eq. (3) to arrive at a solution for the source/sink strength at different locations in the study domain, $20^{\circ}-27.5^{\circ} \mathrm{N}, 75^{\circ}-87.5^{\circ} \mathrm{E}$. However, in order to calculate the gradient terms in Eq. (3) for the edge pixels, an outer domain of size $17.5^{\circ}-30^{\circ} \mathrm{N}$, $72.5^{\circ}-90^{\circ} \mathrm{E}$ was selected for initialising these computations. Since NCEP wind data was available at $2.5^{\circ} \times 2.5^{\circ}$ resolution, the $1^{\circ} \times 1^{\circ}$ (MODIS) AOD was degraded to this level with the criterion that AOD had to be available over a minimum of $60 \%$ of each $2.5^{\circ} \times 2.5^{\circ}$ grid, which otherwise was kept blank. Since the MODIS aerosol retrieval employs different criteria over the land and over the ocean (Kaufman et al., 1997a, b), which can introduce errors in the calculation of gradients in the land-ocean boundaries, the data along the coastline were excluded. The aerosol flux vectors for each pixel at different pressure levels were estimated by multiplying the AOD in that pixel with the mean NCEP winds at its four corners. 
Considering a time interval of one day, the first term on the LHS of Eq. (3) represents the change in AOD from one day to the next in each pixel, while the second and the third terms together constitute aerosol flux divergence. Since aerosol flux can have day-to-day variations, we took the mean of the divergences of two successive days at every time step. All the terms in the LHS of Eq. (3) were computed only if the data for a given pixel was available on both the days. The divergence terms for a pixel were computed only if all four neighbouring pixels were not blank (in AOD). The latitude and longitude step sizes were converted to corresponding distances taking into account the Earth's curvature.

Vertically resolved lidar back scatter profiles over an IGP location, Kharagpur, during the LC-II, observed by Niranjan et al. (2006), indicated a decreasing aerosol extinction with increasing height, with a significant contribution extending up to 1.5 to $2 \mathrm{~km}$. Hence we assume an aerosol extinction vertical profile in the form

$\rho=\rho_{0} \exp \left(-\frac{z}{L}\right)$,

where $\rho_{0}$ is the extinction coefficient per unit volume at the ground and $\mathrm{L}$ is the scale height parameter. Taking $2 \mathrm{~km}$ as the typical scale height, the vertical integration in Eq. (3) is carried out over seven levels (from $1000 \mathrm{hpa}$ to $400 \mathrm{hpa}$ ) following the standard Lagrangian interpolation scheme (Jain et al., 1993) by dividing the entire altitude range into three sections with each comprising of three sub pressure levels.

The RHS of Eq. (3) represents the net rate of aerosol generation in terms of AOD change per day at every pixel. By incorporating the daily AOD data from MODIS along with the NCEP reanalysis of wind field, our attempt here is to arrive at the daily rate of aerosol emission or loss over the study region.

Instead of AOD, another variable that can be considered in the flux continuity Eq. (3) is aerosol mass concentration. But the mass concentration provided by MODIS is derived from other retrieved and assumed parameters like AOD, fine mode fraction, number density, mass density, geometric mean radius, scattering coefficient, etc., of the particles (Remer et al., 2005). While MODIS specifies the uncertainty in AOD $( \pm 0.05 \pm 0.15 \tau$ over land), the accuracy of aerosol mass concentration is not yet determined (Remer et al., 2005), making it less suitable than AOD for using in the continuity equation.

\subsection{Dynamics of aerosol variations during the LC-II period}

During the campaign period, the mean AOD over the Ganga basin showed an oscillation (Fig. 3), with a periodicity of $\sim 4$ to 8 days, with the amplitudes in the second half much larger than that in the first half. After an initial quick drop from 0.49 to 0.32 in four days, it increased to 0.97 by the middle of the third week (19 December), followed by a large oscillation with the peak value occurring on 23 December. The similarity between Figs. 1a and 3 indicates that the observations at Kharagpur during LC-II reflected to a great extent

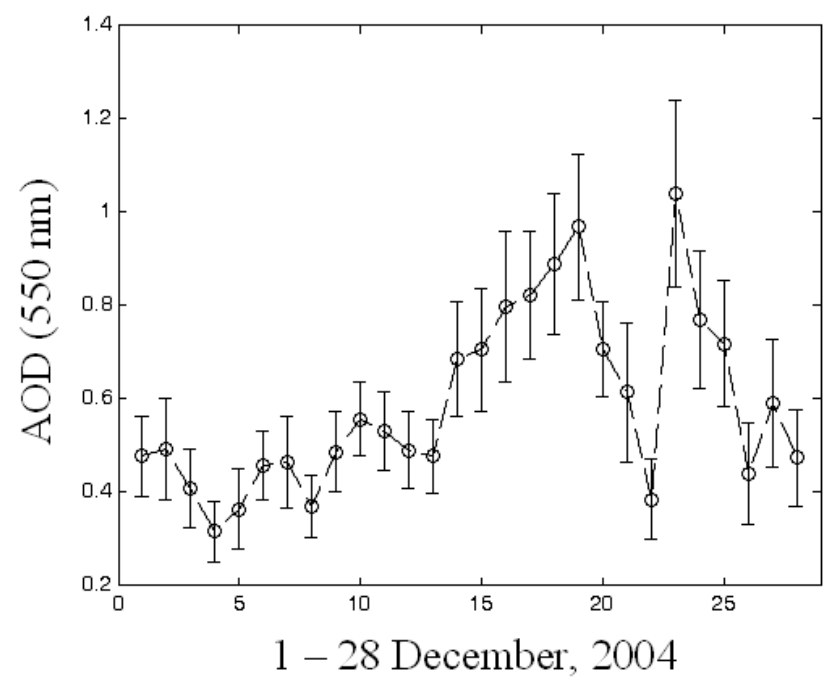

Fig. 3. Daily variations of AOD $(550 \mathrm{~nm})$ averaged over the Ganga basin during LC-II.

the time variation of AOD over the whole Ganga basin. On the days of AOD maxima, fog conditions were reported at the central and western parts of the Ganga basin.

A detailed examination of evolution of AOD over the land mass revealed pockets of high AOD appearing at different locations, which in some cases strengthened and moved along the plain while in some cases weakened fast after an initial growth. The lifetimes of these clusters varied from a few days to a week. The winds at 1000 and $925 \mathrm{hpa} \mathrm{lev-}$ els over this region were generally less than $4 \mathrm{~m} / \mathrm{s}$ with no pronounced gradients in the speed. On the other hand, there were strong convergences in the wind vector field and the aerosol accumulations most of the times were found to lie near the convergences. Figure $4 \mathrm{a}-\mathrm{c}$ show maps of AOD distribution, the wind vector field at 925 hpa and the wind convergence, respectively, for 23 December 2004 as a typical example. In the absence of sources of aerosol generation, we expect the positions and movements of aerosol concentrations to coincide with the wind convergences and dissipate when the convergences weaken. But as can be seen from Fig. $4 \mathrm{a}$ and $\mathrm{c}$, the matching between the locations of high AOD and convergences are not exact. This mismatch cannot arise from errors in AOD, as can be seen that even after allowing a maximum uncertainty in $\mathrm{AOD}( \pm 0.05 \pm 0.15 \tau)$ the two distributions would still differ from each other. On the other hand, such discrepancies can occur, if there are aerosol generation sources and sinks.

By employing the aerosol continuity equation described in Sect. 3.1 an attempt was made to examine the aerosol source strength over the study domain. Figure 5 shows the source distribution for the day, 23 December 2004. The blank portions in the figure result from the absence of aerosol data required for the computation of the flux divergence terms. 


\section{December 23, 2004}
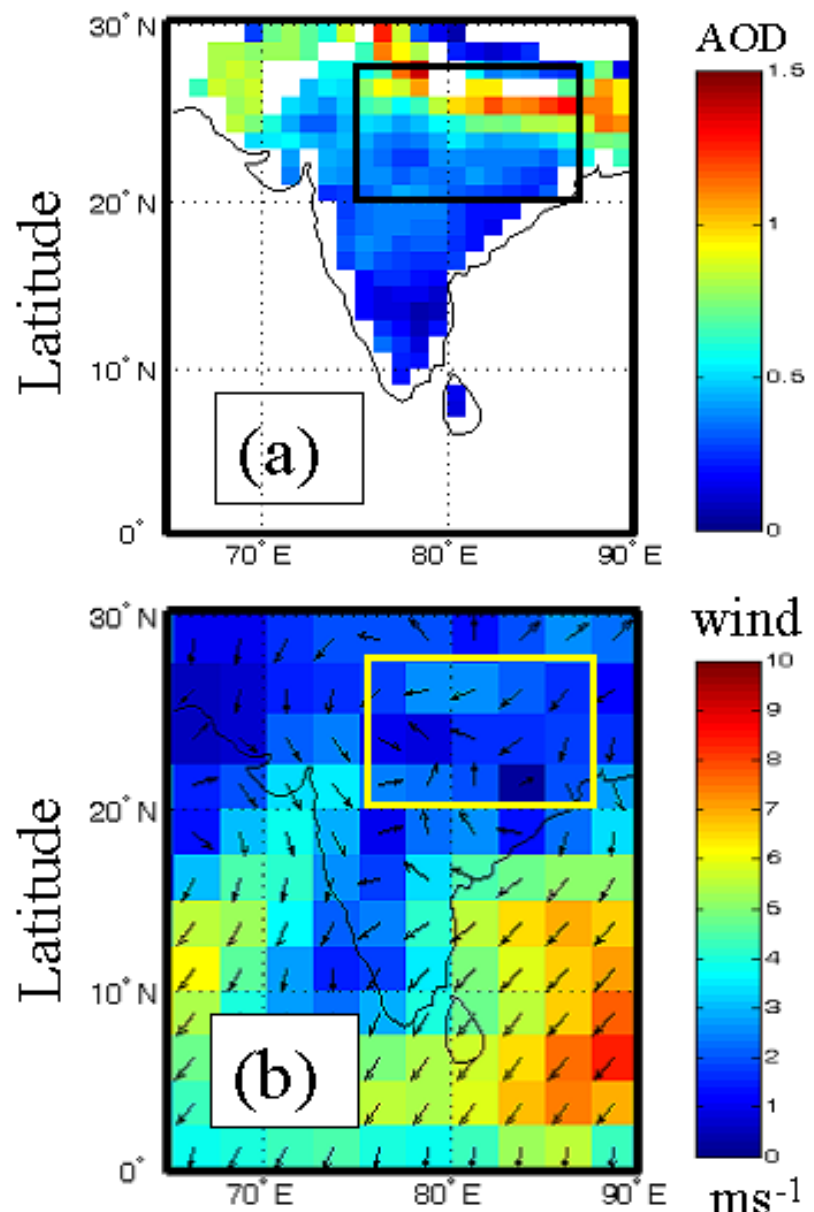

wind
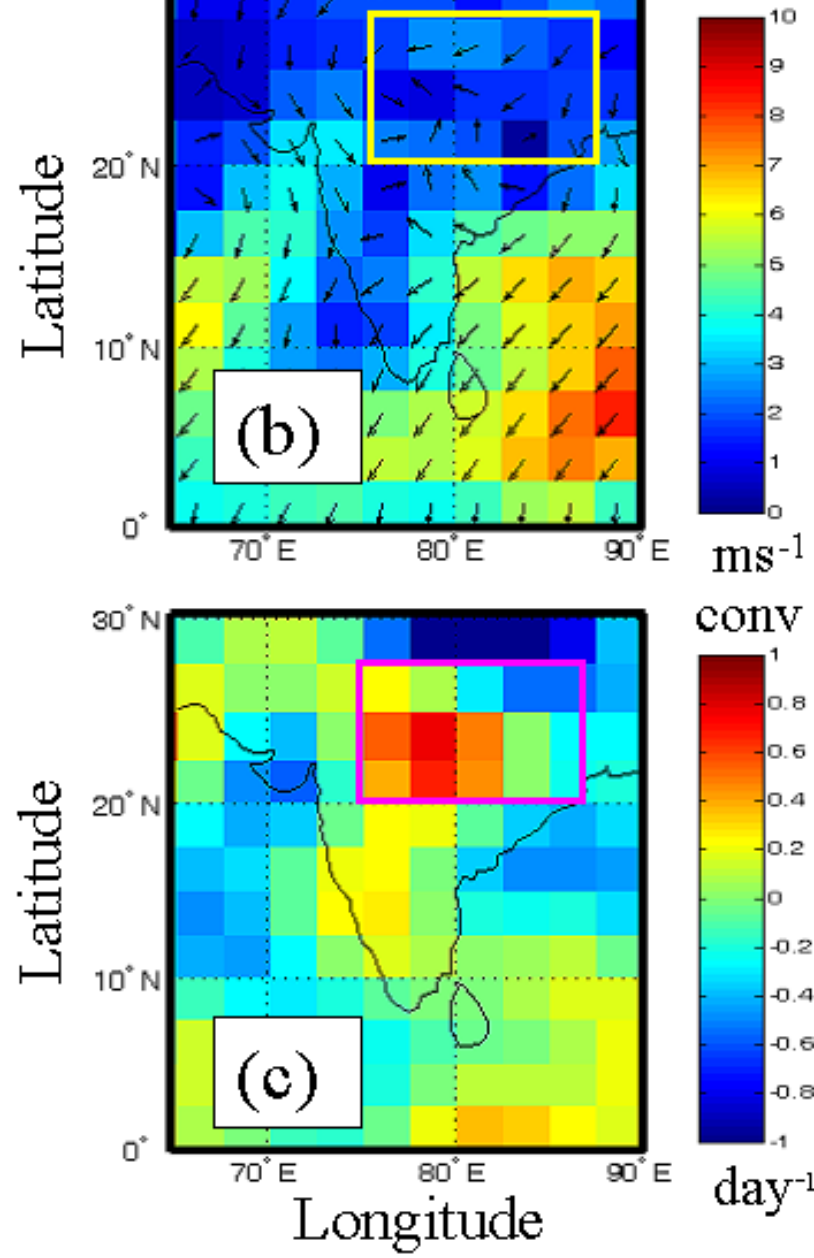

conv

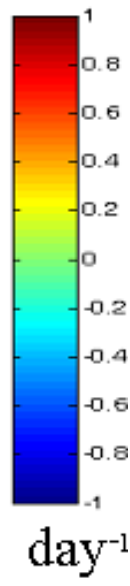

Fig. 4. Spatial distribution of MODIS derived AOD (a) NCEP reanalysis wind field at $925 \mathrm{hpa}$ (b) and NCEP derived wind convergence at 925 hpa (c) on 23 December 2004.

\section{December, 2004}

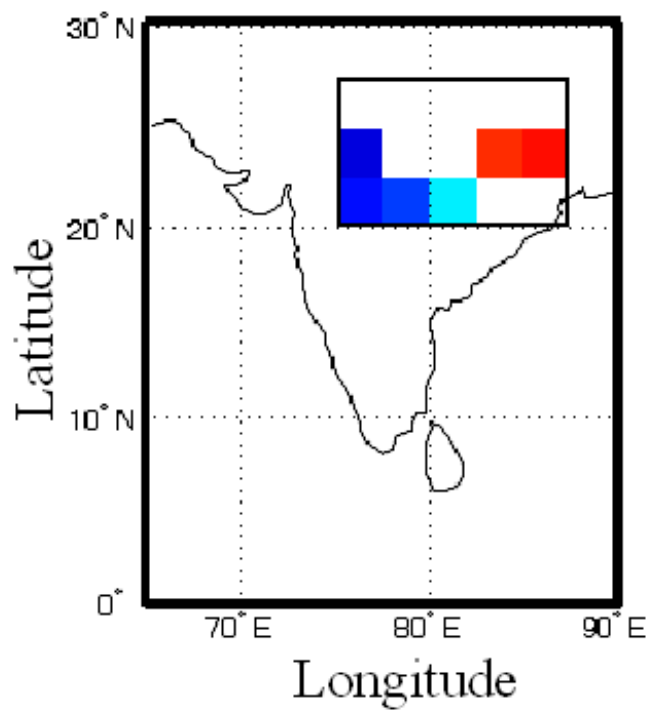

sollice

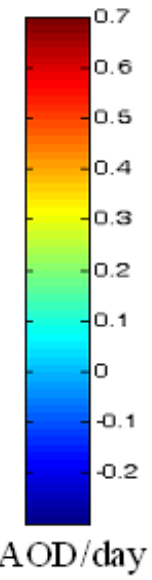

$\mathrm{AOD} /$ day

Fig. 5. Spatial distribution of source strength over the study domain on 23 December 2004.

Since we have used the data only for two days for this part of the analysis, the area covered by the blank region is fairly large. In this figure, positive values indicate aerosol generation and negative values indicate the loss. It can be seen that the source strength is significantly positive in the eastern end of the Ganga basin, indicating the existence of prominent sources. The uncertainty in the source strength resulting from a standard deviation in AOD data $(\sim 15 \%)$ and the uncertainty in aerosol scale height $(\sim 25 \%)$ is $\sim 30 \%$.

Similar computations were performed for all the days during the entire period of the LC-II and the average source strength over the study domain was determined and the result is presented in Fig. 6. In this figure, the blank pixels in the north eastern portion of the study domain are due to the gaps in the original MODIS data over the highly reflecting Himalayan snow regions while the blank pixels in the southeastern portion are a result of the exclusion of AOD data over the coast. In the remaining part of the domain, one can see that positive values are located just west of centre-north, the eastern end and the south western corner. The central region however, shows negative values indicating aerosol loss (beyond the advective changes).

\subsubsection{Aerosol sink model}

The source term " $S$ " in Eq. (3) represents the net source that is the resultant aerosol production over aerosol loss through various removal processes, such as dry/wet deposition, impaction, sedimentation, diffusion, etc. By modelling these loss processes and compensating for them with an appropriate sink term, we can arrive at a better estimate of the actual 


\section{December, 2004}

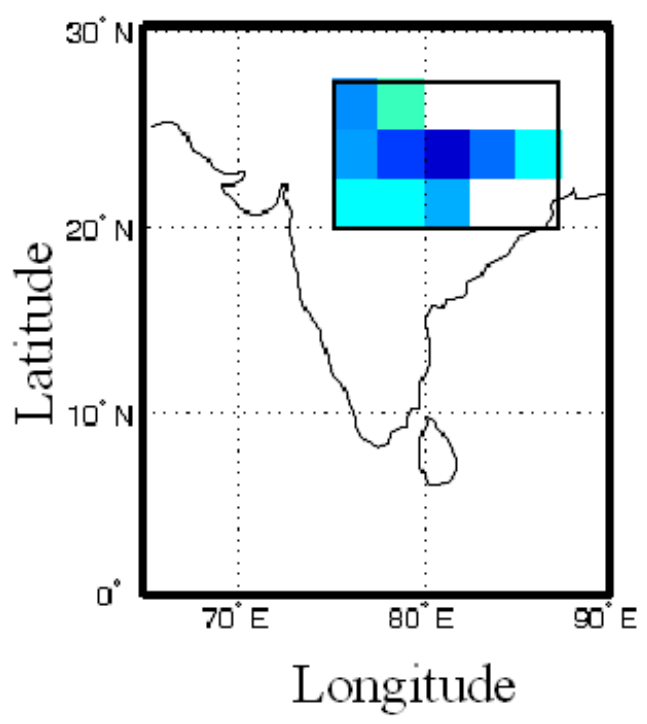

source

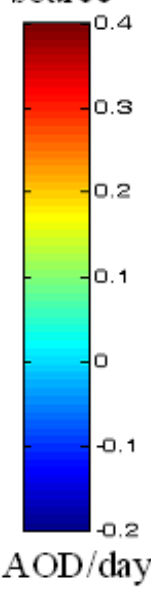

Fig. 6. Spatial distribution of mean source strength averaged for the month of December 2004 over the study domain.

aerosol production. As there was no precipitation and the meteorological conditions were nearly the same over the domain, we assume a uniform model for AOD decrease (in the absence of horizontal transport and aerosol generation) in the form

$\tau=\tau \exp \left(-\frac{t}{D}\right)$,

where $D$ is the aerosol residence time. This corresponds to an $\mathrm{AOD}$ variation at the rate,

$\frac{\partial \tau}{\partial t}=-\frac{\tau}{D}$

which we identify as the sink and introduce in the RHS of Eq. (5). The modified equation, after rearrangement is

$\frac{\partial \tau}{\partial t}+\frac{\tau}{D}+\frac{\partial}{\partial x}\left[\int_{0}^{\infty} \rho u d z\right]+\frac{\partial}{\partial y}\left[\int_{0}^{\infty} \rho v d z\right]=S^{\prime}(x, y, t),(7)$

where $S^{\prime}$ is the source strength compensating for the aerosol loss described by Eq. (5); it is closer to the actual aerosol generation.

Using 2 days as a typical value for $D$, we have used Eq. (7) to re-estimate the average source strength for the month of December 2004 over the study domain. This result, shown in Fig. 7, is discussed in the next section.

\section{December, 2004}

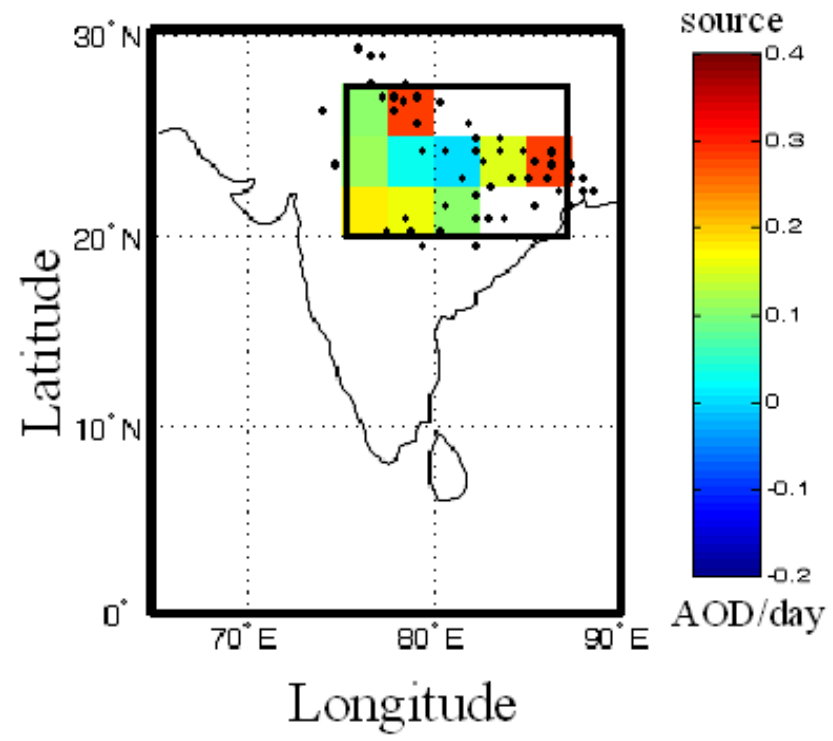

Fig. 7. Spatial distribution of source strength averaged for the month of December 2004 over the study domain, after incorporating aerosol loss model.

\section{Sources of aerosol generation over the Ganga basin}

The Ganga basin is densely populated with abundant, industrial activities. The biofuel consumption is also high in this region. To meet the high energy requirements of the industries, the region also harbours a number of coal fired thermal power plants. Out of $\sim 80$ thermal power plants in India, about $40 \%$ are located over the Ganga basin. The high ash content of the coal, together with inefficient combustion, make these thermal power plants abundant sources of black carbon, nitrate and sulphate particles (http://envfor. nic.in/soer/2001/ind_air.pdf; Reddy and Venkatraman, 2002; Prasad et al., 2006). Keeping this in view, we have examined the location of thermal power plants and their association with high aerosol source strength.

The modified source strength distribution averaged for the campaign period, along with the locations of thermal power plants (represented by black dots) in and around the study region is presented in Fig. 7. It should be noted, however, that the estimated source strength could also have contributions from effects such as relative humidity $(\mathrm{RH})$ variations and the coagulation processes. The mean RH profile from NCEP and its standard deviation during the LC-II period over the domain is shown in Fig. 8, where one can see that the maximum RH does not exceed $\sim 50 \%$. We therefore have neglected the effect of RH on AOD, since it is significant only for values above $\sim 70 \%$ (Parameswaran, 1998). 


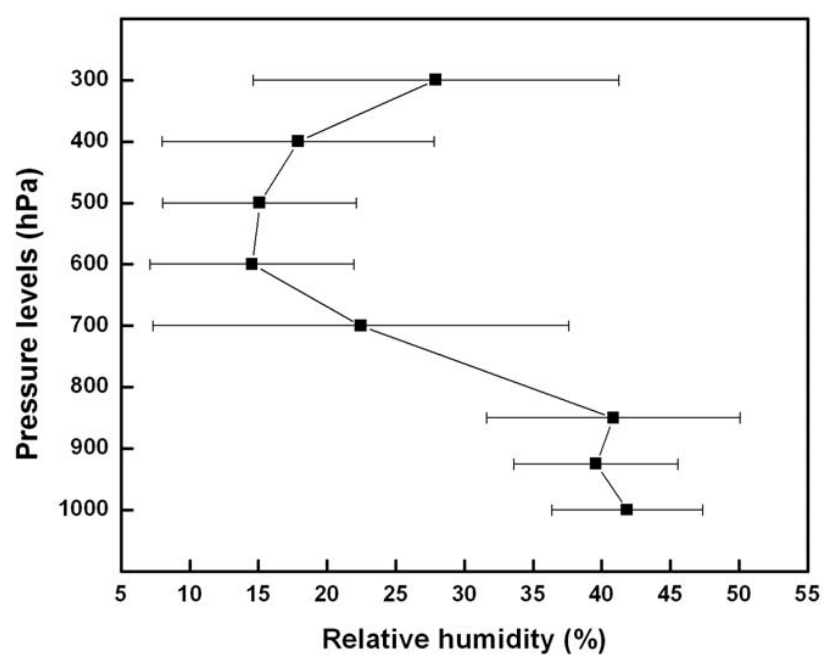

Fig. 8. Mean relative humidity $(\mathrm{RH})$ profile from NCEP and its standard deviation, during the LC-II period averaged over the study domain.

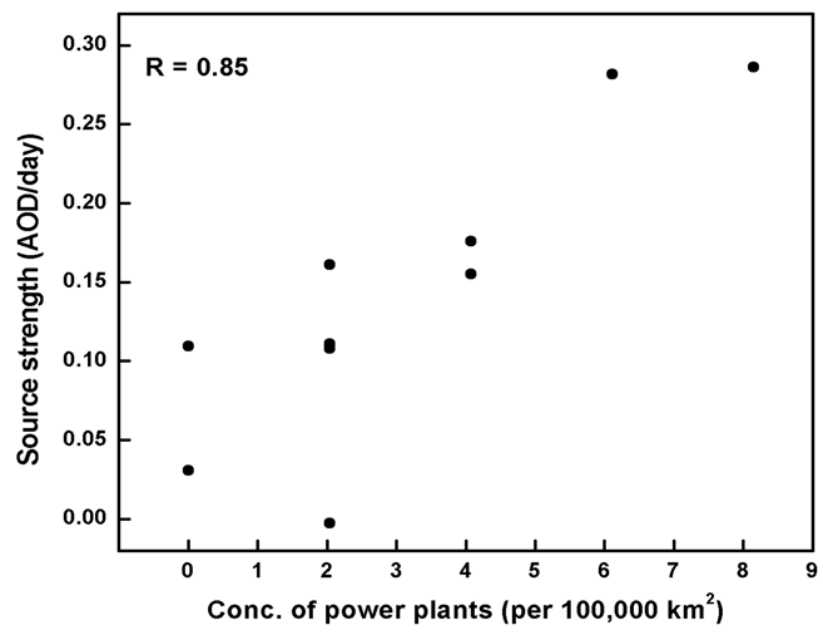

Fig. 9. Scatter plot between the concentration of thermal power plants and the aerosol source strength over the study domain.

In the case of coagulation, smaller particles join together to form large particles, thereby increasing the number of large particles, but at the cost of the loss of smaller particles. Taking these effects into consideration, our computations (McCartney, 1976) with an aerosol size distribution corresponding to a typical polluted urban area (Jaenicke, 1980) showed that the change in AOD per day due to coagulation is at most only $\sim 7.5 \%$ at the locations of major sources over the study domain. Moreover, the nearly same values of the Angstrom exponent from MODIS over the source locations and regions away from them $(0.65 \pm 0.18$ and $0.68 \pm 0.07$, respectively, on average during the campaign) within the domain and the poor correlation $(-0.11)$ between source strength and Angstrom exponent point to the fact that the coagulation process was not a factor that could affect the estimation of the source strength.

\section{December, 2004}

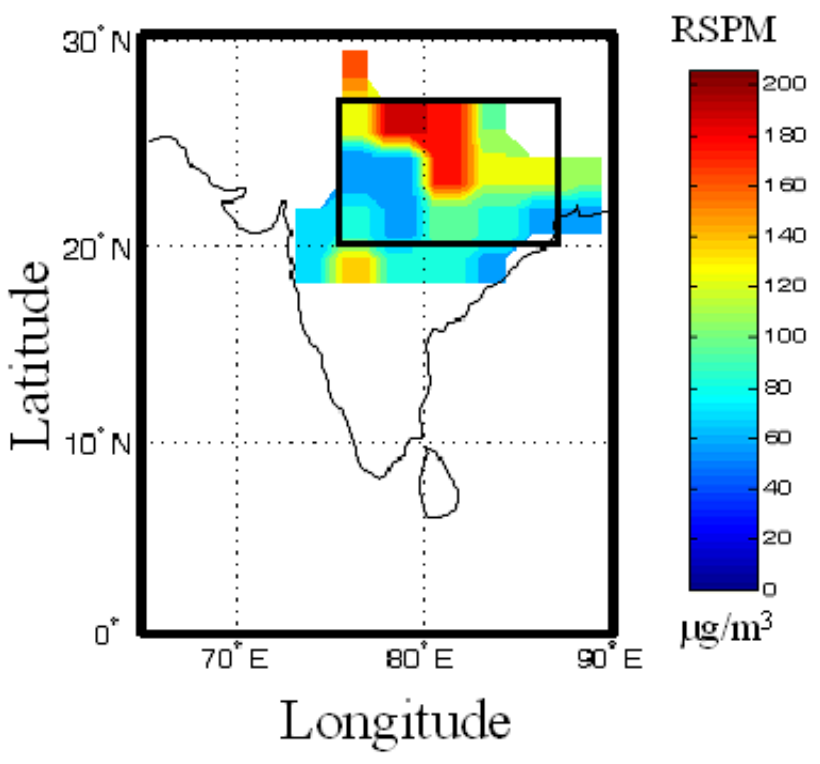

Fig. 10. Mean spatial distribution of RSPM obtained from CPCB over the study domain for December 2004.

As is quite evident from Fig. 7, the locations of high aerosol source strength are seen close to the regions where most of the thermal power plants are located. The uncertainty in the source strength computed at every point arising from the standard deviation of the MODIS AOD $(\sim 15 \%)$ and half a day uncertainty in the assumed aerosol residence time (Jaenicke, 1980) and $\sim 0.5 \mathrm{~km}$ uncertainty in scale height (Niranjan, et al., 2006), is $\sim 38 \%$. With an average emission of $\sim 700 \mathrm{~kg}$ soot and $\sim 85$ tons $\mathrm{SO}_{2}$ per day from each of these power plants (http://www.osc.edu/research/ archive/pcrm/emissions/thermalemissions.shtml), they contribute substantially towards the anthropogenic aerosol load in this region. One can also see in Fig. 7 an aerosol source region of moderate strength in the southwestern parts of the study domain (shown in yellow colour) where the density of thermal power plants is very small. This could be due to higher anthropogenic activities associated with the dense population of this region lying in Maharashtra and Madhya Pradesh, combined with the emission from the existing thermal plants.

We have also made a quantitative comparison between the concentration of thermal power plants and source strength. In order to give equal weight to the aerosol pollution from the power plants lying in all directions, their concentration in each $2.5^{\circ} \times 2.5^{\circ}$ box was determined by defining a circle of influence with diameter $2.5^{\circ}$ and centre in the middle of the box. Figure 9 shows the scatter plot between power plant concentration and source strength, which gives a correlation coefficient of 0.85 , supporting the role of the thermal power plants as a significant source of aerosol production over the Ganga basin. 
In Fig. 10 we show the mean distribution of respirable suspended particulate matter (RSPM) in the $\mathrm{PM}_{10}$ size range within the study domain for December 2004, derived using the data from 29 locations, where regular monitoring is being carried out by the Central Pollution Control Board (CPCB) of India (http://www.cpcb.nic.in). The values were taken from an archive after selecting those stations where a minimum of 15 days data was available. A perusal of this map shows a fair agreement between the RSPM concentrations and the source strength distribution presented in Fig. 7.

\section{Summary and conclusions}

The main purpose of this paper is to investigate the generation and transport of aerosols over the study domain $\left(20^{\circ}-\right.$ $27.5^{\circ} \mathrm{N}, 75^{\circ}-87.5^{\circ} \mathrm{E}$ ) comprising the Ganga basin, where the LC-II campaign was carried out during December 2004. As the first step, the MODIS data was compared with ground based direct measurements (for ground truth) over two sites in the study domain, which showed good agreement. Our analysis showed that a main factor causing high aerosol concentration over the Ganga basin is wind convergence. The incorporation of MODIS derived AOD, along with the NCEP reanalysis wind fields into an aerosol flux continuity equation, indicated the presence of aerosol sources over the Ganga basin. Modification of the flux continuity equation by incorporating an aerosol loss model with residence time of 2 days brought out the aerosol generation sources more clearly. The near coincidence between the locations of aerosol sources and the coal-fired thermal power plants supported by good correlation $(R=0.85)$ between source strength and power plant concentration indicated that the power plants are one of the main contributors for the heavy aerosol loading over the Ganga basin during winter. The spatial distribution of RSPM derived from CPCB data also favours this inference.

Acknowledgements. We acknowledge NASA for providing MODIS aerosol data through EOS data gateway; http://edcimswww.cr.usgs.gov/pub/imswelcome and DAAC website, http://daac.gsfc.nasa.gov. We are grateful to NOAACDC for the reanalysis data provided through their website http://www.cdc.noaa.gov, AERONET Principal investigator and site manager for the aerosol data at Kanpur and the CPCB for the atmospheric pollutant data over the study domain given in their website, http://www.cpcb.nic.in. Thanks are also due to the referees for their suggestions to improve the paper with additional results.

Topical Editor F. D'Andrea thanks two anonymous referees for their help in evaluating this paper.

\section{References}

Ackerman, S., Strabala, K. I., Menzel, W. P., Frey, R. A., Moeller, C. C., and Gumley, L. E.: discriminating clear sky from clouds with MODIS, J. Geophys. Res., 103, 32 139-32 140, 1998.
Charlson, R. J., Schwartz, S. E., Hales, J. M., Cess, R. D., Coakley Jr., J. A., Hansen, J. E., and Hofmann, D. J.: Climate forcing by anthropogenic aerosol, Science, 255, 423-430, 1992.

Chu, D. A., Kaufman, Y. J., Ichoku, C., Remer, L. A., Tanré, D., and Holben, B. N.: Validation of MODIS aerosol optical depth retrieval over land, Geophys. Res. Lett., 29(12), doi:10.1029/2001GL013205, 2002.

Dey, S., Tripathi, S. N., Singh, R. P., and Holben, B. N.: Influence of dust storms on aerosol optical properties over the Indo - Gangetic basin, J. Geophys. Res., 109, D20211, doi:10.1029/2004JD004924, 2004.

Di Girolamo, L., Bond, T. C., Bramer, D., Diner, D. J., Fettinger, F., Kahn, R. A., Martonchik, J. V., Ramana, M. V., Ramnathan, V., and Rasch, P. J.: Analysis of multi-angle imaging spectroradiometer (MISR) aerosol optical depths over greater India during winter 2001-2004, Geophys. Res. Lett., 31, L23115, doi:10.1029/2004GL021273, 2004.

Eck, T. F., Holben, B. N., Dubovik, O., Smirnov, A., Goloub, P., Chen, H. B., Chatenet, B., Gomes, L., Zhang, X.-Y., Tsay, S.-C., Ji, Q., Giles, D., and Slutsker, I.: Columnar aerosol optical depth at AERONET sites in central eastern Asia and aerosol transport to the tropical mid-Pacific, J. Geophys. Res., 110, D06202, doi:10.1029/2004JD005274, 2005.

El-Askary, H., Gautam, R., Singh, R. P., and Kafatos, M.: Monitoring dust storms over Indo- Gangetic basin, J. Indian Soc. Rem. Sens., 32(1), 121-124, 2004.

El-Askary, H., Gautam, R., Singh, R. P., and Kafatos, M.: Dust storm detection over the Indo-Gangetic basin using multi sensor data, Adv. Space Res., 37, 728-733, 2006.

Fisher, R. A.: Statistical methods for research workers, Oliver and Boyd (Edinburgh: Tweddale Court), 211, 14th edition, 1970.

Garg, A., Shukla, P. R., Bhattacharya, S., and Dadhwal, V. K.: Subregion (district) and sector $\mathrm{SO}_{2}$ and $\mathrm{NO}_{\mathrm{x}}$ emissions for India: Assessment of inventories and mitigation flexibility, Atmos. Environ., 35, 703-713, 2001.

Goloub, P., Deuze, J. L., Herman, M., Tanré, D., Chiapello, I., Roger, B., and Singh, R. P.: Aerosol remote sensing over land using the space-borne polarimeter, POLDER, in: Current Problems in atmospheric radiation, edited by: Smith, W. L., and Timofeyev, Yu. M., A. Deepak Publishing, Hampton, Virginia, 113116, 2001.

Hansen, J., Sato, M., and Ruedy, R.: Radiative forcing and climate response, J. Geophys. Res., 102, 6831-6864, 1997.

Haywood, J. R. and Boucher, O.: Estimates of the direct and indirect radiative forcing due to tropospheric aerosols: a review, Rev. Geophys., 38(4), 513-543, 2000.

Holben, B. N., Eck, T. F., Slutsker, I., Tanré, D., Buis, J. P., Setzer, A., Vermote, E., Reagan, J. A., Kaufman, Y. J., Nakajima, T., Lavenu, F., Jankowiak, I., and Smirnov, A.: AERONET - A federated instrument network and data archive for aerosol characterisation, Remote Sens. Environ., 66, 1-16, 1998.

Holben, B. N., Tanré, D., Smirnov, A., Eck, T. F., Slutsker, I., Abuhassan, N., Newcomb, W. W., Schafer, J. S., Chatenet, B., Lavenu, F., Kaufman, Y. J., Castle, J. V., Setzer, A., Markham, B., Clark, D., Frouin, R., Halthore, R., Karnieli, A., O’Neill, N. T., Pietras, C., Pinker, R. T., Voss, K., and Zibordi, G.: An emerging ground- based aerosol climatology: aerosol optical depth from AERONET, J. Geophys. Res., 106, 12 067-12 097, 2001.

Intergovernmental Panel on Climate Change (IPCC): Climate 
change 2001: The Scientific Basis, edited by: Houghton, J. T., Ding, Y., Griggs, D. J., Nouger, M., et al., Cambridge Univ. Press, New York, 896 pp., 2001.

Jaenicke, R.: Atmospheric aerosols and climate, J. Atmos. Sci., 11, 577-588, 1980.

Jain, M. K., Iyengar, S. R. K., and Jain, R. K.: Numerical methods for scientific and engineering computation, Wiley Eastern Limited, 249-251, 1993.

Kaufman, Y. J., Tanré, D., Gordon, H. R., Nakajima, T., Lenoble, J., Frouin, R., Grassl, H., Herman, B. M., King, M. D., and Teillet, P. M.: Passive remote sensing of tropospheric aerosol and atmospheric correction for the aerosol effect, J. Geophys. Res., 102, 16815-16830, 1997a.

Kaufman, Y. J., Tanré, D., Remer, L. A., Vermote, E. F., Chu, A., and Holben, B. N.: Operational remote sensing of tropospheric aerosol over land from EOS moderate resolution imaging spectroradiometer, J. Geophys. Res., 102, 17 051-17 068, $1997 \mathrm{~b}$.

King, M. D., Kaufman, Y. J., Tanré, D., and Nakajima, T.: Remote sensing of Tropospheric Aerosols from Space: Past, Present, and Future, Bull. Am. Meteorol. Soc., 80, 2229-2259, 1999.

Massie, S. T., Torres, O., and Smith, S. J.: Total Ozone Mapping Spectrometer (TOMS) observations of increase in Asian aerosol in winter from 1979 - 2000, J. Geophys. Res., 109, D18211, doi:10.1029/2004JD004620, 2004.

McCartney, E. J.: Optics of the atmosphere, John Wiley \& Sons, New York, 126-127, 1976.

Menon, S., Hansen, J., Nazarenko, L., and Lou, Y.: Climatic effects of black carbon aerosols in China and India, Science, 297, 22502253, 2002.

Morys, M., Mims III, F. M., Hagerup, S., Anderson, S. E., Baker, A., Kia, J., and Walkup, T.: Design, calibration, and performance of MICROTOPS II handheld ozone monitor and sun photometer, J. Geophys. Res., 106(D13), 14 573-14 582, 2001.

Niranjan, K., Sreekanth, V., Madhavan, B. L., and Krishna Moorthy, K.: Wintertime aerosol characteristics at a north Indian site Kharagpur in the Indo-Gangetic plains located at the outflow region into Bay of Bengal, J. Geophys. Res., 111, D24209, doi:10.1029/2006JD007635, 2006.

Parameswaran, K.: Atmospheric aerosols and their radiative effects, PINSA, 64, A(3), 245-266, 1998.

Prasad, A. K., Singh, R. P., and Singh, A.: Variability of aerosol optical depth over Indian Subcontinent: Trend and departures in recent years, J. Indian Soc. Remote Sens., 32(4), 313-316, 2004.

Prasad, A. K., Singh, R. P., and Kafatos, M.: Influence of coal based thermal power plants on aerosol optical thickness in the Indo-Gangetic basin, Geophys. Res. Lett., 33, L05805, doi:10.1029/2005GL023801, 2006.
Prospero, J. M., Charlson, R. J., Mohnen, V., Jaenicke, R., Delany, c., moyere, J., Zoller, W., and Rahn, K.: The atmospheric aerosol system: an overview, Rev. Geophys. Space Phys., 21(7), 16071629, 1983.

Ramanathan, V., Crutzen, P. J., Kiehl, J. T., and Rosenfeld, D.: Aerosols, climate and hydrological cycle, Science, 294, 21192124, 2001.

Ramanathan, V. and Ramana, M. V.: Persistent, wide spread, and strongly absorbing haze over the Himalayan foothills and the Indo - Gangetic basin, Pure Appl. Geophys., 162 , 1609-1626, doi:10.1007/s00024-005-2685-8, 2005.

Reddy, M. S. and Venkataraman, C.: Inventory of aerosol and sulphur dioxide emissions from India:I. Fossil fuel combustion, Atmos. Environ., 36, 677-697, 2002.

Remer, L. A., Tanré, D., Kaufman, Y. J., Ichoku, C., Mattoo, S., Levy, R., Chu, D. A., Holben, B., Dubovik, A., Smirnov, A., Martins, J. V., Li, R.-R., and Ahmad, Z. : Validation of MODIS aerosol retrieval over ocean, Geophys. Res. Lett., 29(12), doi:10.1029/2001GL013204, 2002.

Remer, L. A., Kaufman, Y. J., Tanré, D., Mattoo, S., Chu, D. A., Martins, J. V., Li, R.-R., Ichoku, C., Levy, R. C., Kleidman, R. G., Eck, T. F.,Vermote, E., and Holben, B.N. : The MODIS aerosol algorithm, products and validation, J. Atmos. Sci., 62, 947-973, 2005.

Singh, R. P., Dey, S., Tripathi, S. N., and Tanré, V.: Variability of aerosol parameters over Kanpur, northern India, J. Geophys. Res., 109, D23206, doi:10.1029/2004JD004966, 2004.

Takemura, T., Okamoto, H., Maruyama, Y., Namaguti, A., Higurashi, A., and Nakajima, T.: Global three-dimensional simulation of aerosol optical thickness distribution of various origins, J. Geophys. Res., 105(D14), 17 853-17 873, 2000.

Tanré, D., Kaufman, Y. J., Herman, M., and Mattoo, S.: Remote sensing of aerosol properties over oceans using the MODIS/EOS spectral radiances, J. Geophys. Res., 102, 16 971-16 988, 1997.

Tripathi, S. N., Dey, S., Chandel, A., Srivastava S., Singh, R. P., and Holben, B. N.: Comparison of MODIS and AERONET derived aerosol optical depth over the Ganga Basin, India, Ann. Geophys., 23, 1093-1101, 2005, http://www.ann-geophys.net/23/1093/2005/.

Venkataraman, C., Habib, G., Eiguren- Fernandez, A., Miguel, A. H., and Friendlander, S. K.: Residential biofuels in South Asia: Carbonaceous aerosol emissions and climate impacts, Science, 307, 1454-1456, 2005. 